\title{
Preemptive analgesia I: physiological pathways and pharmacological modalities
}

\section{[L'analgésie préventive I: mécanismes physiologiques et modalités}

pharmacologiques]

Dermot J. Kelly MrCPI FFARCSI, * Mahmood Ahmad MD, $†$ Sorin J. Brull MD†

Purpose: This two-part review summarizes the current knowledge of physiological mechanisms, pharmacological modalities and controversial issues surrounding preemptive analgesia.

Source: Articles from 1966 to present were obtained from the MEDLINE databases. Search terms included: analgesia, preemptive; neurotransmitters; pain, postoperative; hyperalgesia; sensitization, central nervous system; pathways, nociception; anesthetic techniques; analgesics, agents.

Principal findings: The physiological basis of preemptive analgesia is complex and involves modification of the pain pathways. The pharmacological modalities available may modify the physiological responses at various levels. Effective preemptive analgesic techniques require multi-modal interception of nociceptive input, increasing threshold for nociception, and blocking or decreasing nociceptor receptor activation. Although the literature is controversial regarding the effectiveness of preemptive analgesia, some general recommendations can be helpful in guiding clinical care. Regional anesthesia induced prior to surgical trauma and continued well into the postoperative period is effective in attenuating peripheral and central sensitization. Pharmacologic agents such as NSAIDs (non-steroidal anti-inflammatory drugs) opioids, and NMDA (Nmethyl-D-aspartate) - and alpha-2-receptor antagonists, especially when used in combination, act synergistically to decrease postoperative pain.

Conclusion: The variable patient characteristics and timing of preemptive analgesia in relation to surgical noxious input requires individualization of the technique(s) chosen. Multi-modal analgesic techniques appear most effective.

Objectif : La présente revue, en deux parties, résume les connaissances actuelles sur les mécanismes physiologiques et les modalités pharmacologiques de l'analgésie préventive ainsi que sur les questions controversées qui l'entourent.
Sources : Des articles, de 1966 à aujourd'hui, obtenus à partir des bases de données MEDLINE. Les termes de la recherche comprennent : analgesia, preemptive; neurotransmitters; pain, postoperative; hyperalgesia; sensitization, central nervous system; pathways, nociception; anesthetic techniques; analgesics, agents.

Constatations principales : Les fondements physiologiques de l'analgésie préventive sont complexes et impliquent une modification des mécanismes de la douleur. Les modalités pharmacologiques disponibles peuvent modifier les réponses physiologiques à différents niveaux. Les techniques efficaces d'analgésie préventive exigent l'interception multimodale du stimulus nociceptif, la hausse du seuil de nociception et le blocage ou la baisse de l'activation des récepteurs de nociception. Même si la documentation est controversée concernant l'efficacité de l'analgésie préventive, certaines recommandations générales peuvent guider les soins cliniques. L'anesthésie régionale induite avant le trauma chirurgical et poursuivie après l'opération est efficace pour diminuer la sensibilisation centrale et périphérique. Les agents pharmacologiques comme les AINS (anti-inflammatoires non stéroïdiens), les opioïdes et les antagonistes des récepteurs alpha-2 et NMDA (N-méthyl-D-aspartate), surtout lorsqu'ils sont combinés, agissent en synergie pour réduire la douleur postopératoire.

Conclusion : La diversité des patients et le moment choisi pour administrer l'analgésie préventive en relation avec le stimulus chirurgical nocif demandent l'individualisation de la, ou des, technique choisie. Des techniques analgésiques multimodales semblent plus efficaces.

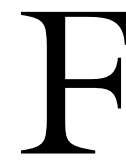

EW sensations are as disturbing to the individual as that of pain. It stands alone among man's sensations, because it is accompanied by strong psychological and emotional components. This is recognized by the International Association for the Study of Pain (IASP), which

From the Department of Anaesthesia, ${ }^{*}$ Cork University Hospital, Wilton, Cork, Ireland, and the Department of Anesthesiology, $†$ University of Arkansas for Medical Sciences, Little Rock, Arkansas, USA.

Address correspondence to: Dr. Sorin J. Brull, Professor and Chairman, Department of Anesthesiology, University of Arkansas for Medical Sciences, 4301 W. Markham Street, Slot 515, Little Rock, AR 72205-7199, USA. Phone: 501-686-6119; Fax: 501-603-1421; E-mail: Sorin.Brull@uams.edu

Accepted for publication November 2, 2000.

Revision accepted July 11, 2001. 
defines pain as "an unpleasant sensory and emotional experience associated with actual or potential tissue damage or described in terms of such damage".

At the beginning of the last century, Crile was among the first to introduce the concept of treating pain prior to its onset: preemptive analgesia. ${ }^{1,2} \mathrm{He}$ observed that if pain transmission was blocked prior to the initial surgical incision, postoperative mortality was decreased. This analgesic technique was proposed initially as a means for preventing postoperative shock; however, proponents of this technique, later termed preemptive analgesia, also noted a marked decrease in the intensity (and duration) of postoperative pain.

The last 20 years have seen significant scientific advancement in our understanding of the physiology, pathophysiology and pharmacology of pain. In conjunction with this knowledge, there has been a resurgence of the concept of preemptive analgesia and numerous studies have addressed the purported benefits of this technique in the surgical patient. This review summarizes current knowledge of the pain pathways, mechanisms and neurotransmitters, and describes new aggressive approaches to acute pain management in the context of preemptive analgesia.

\section{Physiologic pathways}

Specialized receptors provide information to the central nervous system (CNS) about the state of the environment in the vicinity of the organism. Each receptor is specialized to detect a particular type of stimulus (e.g., touch, temperature, pain, etc.) Those receptors in the skin and other tissues that sense pain are free nerve endings, while those for temperature detection can be free nerve endings, bulbs of Krouse or Ruffini's corpuscles. Receptors are distributed with varying densities in different tissues. Pain receptors may be stimulated by mechanical damage, extremes of temperature, or by irritating chemical substances. While certain pain receptors are responsive to only one of the above stimuli, most can be stimulated by two or more. When the pain receptors in peripheral tissues (such as skin) are stimulated, the nociceptive (pain) impulses are transmitted to the CNS by two distinct types of neurons - the A-delta and $\mathrm{C}$ nerve fibres. The A-delta fibres are large-diameter, fast conducting myelinated fibres, which transmit "first" pain - sharp, prickling, and injurious. The C fibres are small-diameter, slower conducting unmyelinated fibres that are responsible for "second" pain dull, aching and visceral type. The primary afferent sensory neurons from the periphery then enter the spinal cord and synapse with neurons in the dorsal horn. The second-order neurons, arising from the dorsal horn, have long axons that decussate in the anterior commis- sure and travel cephalad in the contralateral anterolateral pathway (also known as spinothalamic tract). Some of the long axons that synapsed with type $\mathrm{C}$ neurons do not decussate, but pass cranially in the ipsilateral anterolateral spinal pathway. The anterolateral spinal pathway fibres terminate in the thalamus, from which neuronal relays are sent to other CNS centres and the sensory cortex. These higher centres are responsible for the perception of pain and the emotional components that accompany it.

There are four distinct processes in the sensory pathway: transduction, transmission, modulation and perception (Figure 1). Each of these processes presents a potential target for analgesic therapy; therefore their physiology is described in some detail below.

\section{Transduction}

Nociceptors, the pain receptors, respond selectively to noxious stimuli and convert chemical, mechanical, or thermal energy at the site of the stimulus into neural impulses, a process known as transduction (Figure 2). The primary afferent nociceptors are the terminal branches of the A-delta and C fibres, whose cell bodies are located in the dorsal root ganglia. Mendell ${ }^{3}$ described a functional classification of nociceptive nerve fibres. Wide-dynamic range (WDR) neurons are those that receive input from both noxious and non-noxious

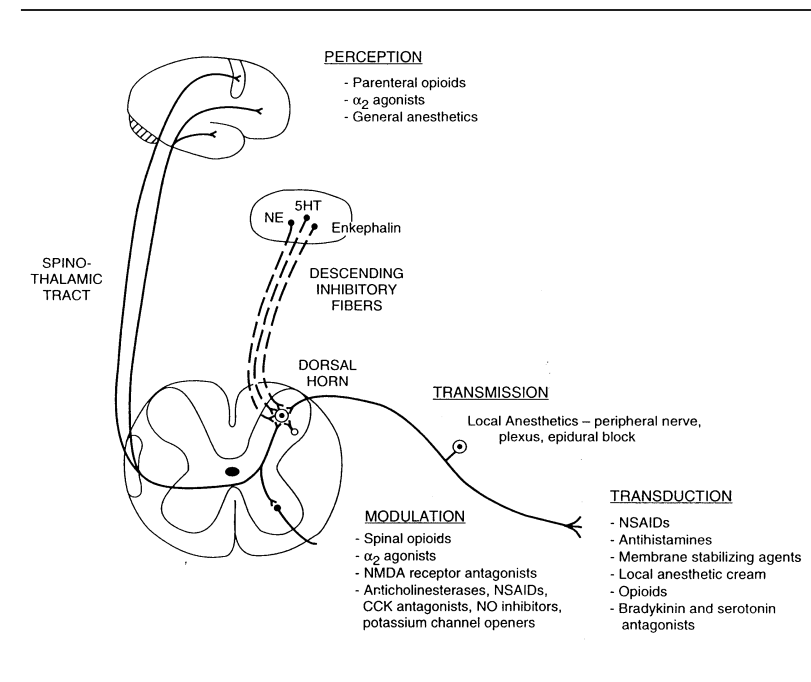

FIGURE 1 Diagrammatic representation of the four processes involved in the sensory pathway: transduction, transmission, perception, and modulation. Primary afferent neurons transmit information from the periphery to the dorsal horn of the spinal cord. Afferent information is then transmitted via the spinothalamic tracts by second-order neurons to the thalamus and to the sensory cortex. The descending inhibitory fibres (interrupted lines) modulate the afferent input at the dorsal horn. Also represented are the agents that can modify the sensory input of each of the four processes. 
IRANSDUCTION

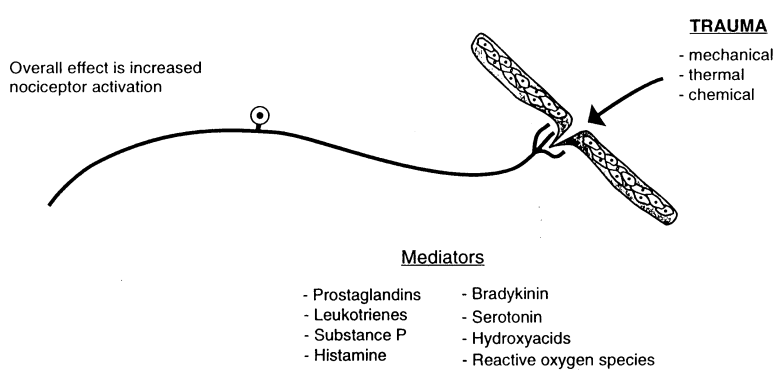

FIGURE 2 Representation of the transduction process and the mediators of inflammatory processes that lead to peripheral sensitization of nociceptors.

IRANSMISSION

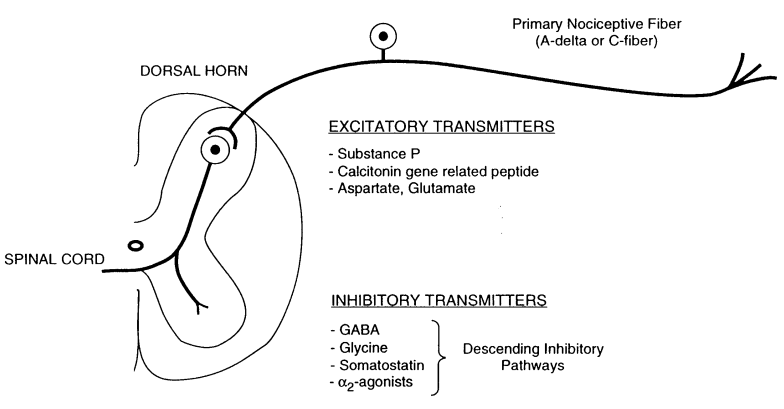

FIGURE 3 Representation of the transmission process by primary afferent (A-delta and C) fibres from periphery to the dorsal horn of the spinal cord. The balance between excitatory and inhibitory transmitter release determines the intensity of afferent information and the state of sensitization that occurs following peripheral injury.

stimuli and that exhibit a graded response (i.e., they can increase their firing rate in response to increasing levels of stimulation); the high-threshold (HT) neurons are those that are activated only by noxious (HT) stimulation; and low-threshold (LT) neurons are those activated only by non-noxious (LT) stimulation.

When the A-delta and C fibres are activated by brief intense stimuli, with little accompanying tissue damage, the resulting transient pain serves as a physiological warning. However, when nociceptors are activated by the noxious stimuli that accompany tissue damage or infection, a regional injury response occurs in the periphery. Chemical substances and enzymes are released from the damaged tissues, increasing the transduction of painful stimuli. Prostanoids (prostaglandins, leukotrienes and hydroxyacids) are products of the arachidonic acid pathway and are major mediators of the hyperalgesia that accompanies inflammation. Prostaglandins (PGs) and leukotrienes cause sensitization of the peripheral receptors, reducing their activation threshold and increasing their responsiveness to other stimuli. ${ }^{4-6}$ Kinins, such as bradykinin and kallidin have numerous pro-inflammatory functions including: release of PGs, cytokines and free radicals from a variety of cells; degranulation of mast cells and release of histamine; and stimulation of sympathetic neurons to alter blood vessel caliber. ${ }^{7}$ Kinins also contribute to plasma extravasation by producing contraction of vascular endothelial cells. ${ }^{8}$ Bradykinin and PGs, particularly $\mathrm{PGE}_{2}$, stimulate neurons directly, initiating the transmission of pain impulses along the nociceptive pathway. Peripheral vascular dilation and increased vascular permeability are induced by the release of substance $P$ caused by the axon reflex of the injured nerve. ${ }^{9}$ This increased vascular permeability, accompanied by release of vasoactive mediators from mast cells, results in an inflammatory response (neurogenic edema). ${ }^{10}$ The increased vascular permeability also results in extravasation of additional algogenic (pain producing) substances, such as histamine and serotonin. Histamine can also be released from mast cells during degranulation, a process promoted by substance $P$, kinins, interleukin- 1 and nerve growth factor. Histamine acts on sensory neurons to produce pain and itching. ${ }^{11}$ Histamine stimulation of sensory neurons may evoke release of neuropeptides and PGs, leading to further inflammatory effects and hyperalgesia. ${ }^{12}$ Serotonin $(5-\mathrm{HT})$ is a major inflammatory mediator, especially in the initial phases of the inflammatory response. ${ }^{13,14}$ Released from mast cells and platelets during injury or inflammation, 5-HT causes direct activation of sensory neurons via 5 - $\mathrm{HT}$ type $3\left(5-\mathrm{HT}_{3}\right)$ receptor activation. Nociceptive impulses activating the sympathetic nervous system promote norepinephrine release, which in turn accelerates sensitization of the nociceptors, creating another vicious cycle ${ }^{8}$ Reactive oxygen species, such as hydrogen peroxide, superoxide, and hydroxyl species, are produced by tissues during inflammation. These substances have been shown to enhance the effects of bradykinin, $\mathrm{PGE}_{2}$ and other inflammatory mediators, ${ }^{15}$ similar to the synergism between other algogenic substances, such as PGs, bradykinin, and 5-HT.

In summary, the activity and sensitivity of sensory neurons is profoundly altered by the mediators 
released as a result of tissue injury and inflammation (Figure 2). These inflammatory mediators produce an increase in nociceptor sensitivity, neurogenic edema and hyperalgesia of tissues in the vicinity of the injury. These complex changes in peripheral signal processing result in increased pain sensation, alteration in the quality and duration of pain, and may lead to altered central pain processing and the development of chronic pain states.

\section{Transmission in the dorsal horn}

When signal transduction has occurred, impulses are transmitted via A-delta and $\mathrm{C}$ fibres to the dorsal horn of the spinal cord (Figure 3 ). The nerve fibres synapse in the superficial layers of Rexed laminae: the A-delta neurons synapse in laminae I, II and V, and the C fibres in laminae I and II. The borders between these laminae are not distinct. In addition, there is considerable overlap of neuronal cell types between the laminae, with each lamina containing more than one type of neuron. ${ }^{16} \mathrm{~A}$ variety of neurotransmitters are released by the incoming first order nociceptive neurons. One of these is substance $\mathrm{P}$, a neurokinin, which is released from HT fibres. The calcitonin gene-related peptide (CGRP) is released along with substance $\mathrm{P},{ }^{17,18}$ and extends the spinal cord zone from which substance $\mathrm{P}$ is released, thereby contributing to increased excitability. ${ }^{19}$ In turn, substance $\mathrm{P}$ induces the release of excitatory amino acids (EAAs) such as aspartate and glutamate, which act on the AMPA (2amino-3-hydroxy-5-methyl-4-isoxazole-propionic acid) and NMDA (N-methyl-D-aspartate) receptors. ${ }^{20}$ Enhanced synaptic transmission due to release of EAAs follows substance $\mathrm{P}$ release ${ }^{21}$ and the latter can induce a prolonged enhancement of responses by dorsal horn neurons to glutamate or NMDA. ${ }^{22,23}$ This enhanced depolarization causes calcium influx into postsynaptic neurons, which induces persistent changes in the excitability of the cell. ${ }^{8}$ The term "wind-up" has been used to describe the enhanced excitability and sensitization of dorsal horn cells induced by the above mechanisms (Figure 3 ).

In addition to causing "wind up", repeated noxious stimulation of the dorsal horn may result in an increase in the number of neurons in laminae I and II whose nuclei express C-fos protein, a protein thought to be involved in the memory of pain. ${ }^{24,25}$ Pretreatment with morphine has been shown to decrease the number of cells expressing Cfos protein. This suggests that preventing access of the trigger signal to the CNS may attenuate the increased sensitivity to painful stimuli, and reduce the hyperalgesia and production of pain by non-painful stimuli (i.e., allodynia), which accompany tissue injury. ${ }^{24,25}$
Perception

The second order nociceptive afferent fibres have their cell bodies in the dorsal horn of the spinal cord, from which they project axons to the higher CNS centres responsible for processing of nociceptive information. As mentioned previously, most of the ascending fibres decussate before travelling cranially in the spinothalamic tract. The majority of the neurons comprising the spinothalamic tract are WDR or HT neurons; ${ }^{26}$ they course through the pons, medulla and mid-brain to terminate in specific portions of the thalamus. From the thalamus, afferent information is carried to the somatosensory cortex. The spinothalamic tract also sends collateral branches to the reticular formation. The impulses transmitted via these tracts are responsible for the sensory discrimination of pain and the emotional responses it evokes. The reticular formation is probably responsible for the increased arousal and aspects of the emotional-affective components of pain, as well as somatic and autonomic motor reflexes. ${ }^{27-29}$ The activation of supraspinal structures is mediated by EAAs, ${ }^{30}$ but the neurotransmitters involved in central processing of nociceptive information have not yet been elucidated.

Analgesic therapy has traditionally targeted the pain perception component of the analgesic pathway. Certain areas, such as the nucleus reticularis gigantocellularis, one of the nuclei in which nociceptive second-order neurons terminate, are profoundly depressed by both general anesthetics and opioid analgesics. ${ }^{31-34}$ Despite this fact, traditional analgesic therapy using opioids has met with varying success due, in part, to the lack of binding specificity of parenteral and oral opioids. With the increasing understanding of the pain pathways and the processes involved therein, it is now recognized that pain is best controlled by using several analgesic agents, each of which acts on a specific site along the pain pathway. Such an approach also lessens the reliance on one particular agent or mechanism, and the resulting synergism may avoid the side effects associated with high doses of individual agents.

Efferent pathways and pain modulation

In the early twentieth century, Sherrington ${ }^{35}$ emphasized the importance of the interaction between excitatory and inhibitory neuronal systems in the processing of incoming sensory information by the brain. It is now known that efferent pathways help to modify afferent nociceptive information. The efferent neuronal pathways involved in pain modulation include: the corticospinal tracts, which commence in the motor cortex and synapse in Rexed laminae III-IV; hypothalamic efferents, which arise in the hypothalamus and synapse 
in the mid-brain, pons, medulla and Rexed lamina I; and extensive efferent fibres from the periaqueductal gray matter in the mid-brain and the nucleus raphe magnus in the medulla, to the dorsal horn. Stimulation of these efferent (descending) pathways can modulate nociceptive transmission in the periphery, in the spinal cord by altering neurotransmitter release, or supraspinally by activation of inhibitory pathways (Figure 1). It is well established that norepinephrine, serotonin and opiate-like substances (endorphins) are involved in the brainstem inhibitory pathways that modulate pain in the spinal cord. ${ }^{36-38}$

Gamma-amino butyric acid (GABA) and glycine are two important inhibitory neurotransmitters that act at the dorsal horn. Blockade of spinal GABA or glycine can result in allodynia, by removing inhibitors that control NMDA receptors. ${ }^{39}$ Failure of spinal inhibition may thus play a role in the etiology of neuropathic pain. Alternatively, when there is peripheral inflammation, the opposite effect can be seen: up-regulation of spinal GABA receptors promotes inhibition of afferent nociceptive impulses ${ }^{40}$ and decreased pain sensation. Therefore, the sensitivity of spinal GABA receptors can vary under different circumstances, resulting in modulation of nociceptive information.

Another neurotransmitter, somatostatin, is found in cells of the dorsal root ganglion and in afferent terminals of the dorsal horn of the spinal cord. It appears to be released in response to noxious stimuli, resulting in hyperpolarization and a reduced firing rate in dorsal horn neurons. ${ }^{41}$ However, although it appears to have beneficial analgesic properties, intrathecal administration of somatostatin can also result in motor dysfunction and paralysis at doses just above those which produce analgesia. Thus, further studies are required to fully evaluate the role of this peptide in antinociception. ${ }^{41}$

Galanin is found in a large percentage of primary afferent nociceptive fibres, and is thought to be an inhibitory peptide. It is frequently co-localized with substance $P$ and CGRP. Until development of an antagonist, however, the exact role of galanin in nociceptive transmission is unlikely to be elucidated. ${ }^{40}$

\section{Mechanisms of hypersensitivity}

The transmission of pain from peripheral tissues via the spinal cord to the brain is not a simple process, with its own exclusive pathways; rather, it is dependent on the balance between excitatory and inhibitory neuronal systems.

Peripheral tissue injury can modify the responsiveness of the nervous system to stimuli at two sites: peripheral sensitization, which entails a reduction in the threshold of nociceptive afferent peripheral terminals; and central sensitization, an activity-dependent increase in the excitability of spinal neurons. ${ }^{42}$ These two processes contribute to the postinjury state of hypersensitivity seen postoperatively. This state manifests as an increase in the response to noxious stimuli and a decrease in the pain threshold. It is now apparent that the receptive field of dorsal horn cells is not fixed, and can undergo a number of changes. These changes include alterations in the size and location of the peripheral receptive field (spatial component); changes in the sensitivity to different stimuli (threshold component); changes in the selectivity of the receptor to mechanical, thermal or chemical stimuli (modality sensitivity component); or a change in activity of the receptor in relation to the timing of the stimulus (temporal component). ${ }^{43}$ Primary hyperalgesia refers to receptor field changes within the area of injury, while secondary byperalgesia refers to changes in the undamaged tissue surrounding the area of injury. In addition, these changes are responsible for the misperception of pain in response to non-noxious stimuli - termed allodynia. ${ }^{42}$ Primary hyperalgesia is explained by sensitization of peripheral nociceptors, ${ }^{44-46}$ while secondary hyperalgesia may be caused by altered CNS processing of mechanoreceptor impulses from peripheral tissues. ${ }^{45,47-50}$

Clinical pain may be divided into two entities: inflammatory pain, which is the consequence of trauma to peripheral tissues (i.e., surgical incision, dissection, burns, etc); and neuropathic pain, which is the result of direct injury to nervous tissue (i.e., nerve transection). Both types of injury result in long-term changes in the sensitivity of the nervous system, such that the intensity of subsequent stimuli necessary to induce pain is reduced.

\section{Pharmacological modalities}

Preemptive analgesia is an antinociceptive therapy whose aim is to prevent both peripheral and central sensitization, thereby attenuating (or, ideally, preventing) the postoperative amplification of pain sensation. Treatment can be aimed at the periphery, at inputs along sensory axons, or at CNS sites using single or combinations of analgesics applied either continuously or intermittently.

\section{Regional anesthesia}

Afferent blockade of all impulses, and in particular nociceptive impulses, prior to incision is central to the concept of preemptive analgesia. This can be achieved with local infiltration for superficial procedures, peripheral nerve or plexus anesthesia, or central neuraxial blockade. Of importance is the fact that effective analgesia should not only be well established prior to the surgical incision but should be continued well into the postop- 
erative period. The timing to stop delivery of the local anesthetic agent should be judged against the healing of the wound and degree of anticipated tenderness. Discontinuation of regional blockade when significant afferent input is still likely to be present would merely delay the onset of surgical pain until after the pharmacologic effects of the local anesthetic subside. In patients with preexisting central sensitization, the regional blockade should be continued for a longer duration in order to achieve a lower level of nociceptive input. Often, regional anesthesia is combined with adjuvant therapy in the postoperative period.

Non-steroidal anti-inflammatory drugs (NSAIDs)

Peripheral sensitization, in which there is an increase in the sensitivity of HT peripheral sensory neurons, results from exposure of sensory nerve terminals to algogenic substances and mediators released locally at the site of injury. The aim of treatment should be to prevent the release (or to inactivate) the various neurotransmitters and inflammatory mediators, which sensitize the peripheral nociceptors. By reducing PG synthesis, cyclo-oxygenase inhibitors block the nociceptive response to endogenous mediators of inflammation, with the effect being greatest in tissues that have been subjected to injury and trauma. ${ }^{51}$ NSAIDs represent diverse chemical entities, but their common mechanism of action is inhibition of this PG-mediated sensitization of nociceptors to chemical and mechanical irritants. ${ }^{52}$ Moreover, membrane stabilization by NSAIDs may account for the decrease in PG release seen at concentrations insufficient for effective inhibition of cyclo-oxygenase. ${ }^{51}$ Glucocorticoids, tricyclic antidepressants, anti-arrhythmics and local anesthetics may work by a similar mechanism, as all are considered to possess membrane-stabilizing effects.

Central neuronal tissues also synthesize PGs, and spinally administered NSAIDs have been shown to reduce hyperalgesia. To what extent the central action of NSAIDs contributes to the analgesic effect of systemically administered NSAIDs is unknown. ${ }^{53}$ It is apparent that in addition to their effects on PG synthesis, certain NSAIDs also affect the synthesis and activity of other neuroactive substances, such as 5-HT, kynurenic acid and polyamines, thought to play important roles in the processing of nociceptive impulses in the dorsal horn. ${ }^{54}$

\section{Opioids}

At the spinal cord, modulation of afferent input can be accomplished by decreasing neurotransmitter release, by blocking the postsynaptic receptors (thereby blocking the effects of the neurotransmitters), or by activat- ing inhibitory pathways. Opioid receptors are a key site of analgesia production and recent studies indicate that spinal opioid systems can be enhanced or reduced under different circumstances. ${ }^{40}$ The lamina I and the substantia gelatinosa in the dorsal horn, the zones in which $\mathrm{C}$-fibres terminate, have the highest concentrations of opioid receptors in the spinal cord. Approximately $70 \%$ of the total opioid receptors in the rat spinal cord are of the mu-subtype, approximately $24 \%$ are delta, and approximately $6 \%$ are kappa receptors. ${ }^{55}$ Whether this situation mirrors that in humans is under investigation, but molecular biology has demonstrated close similarities between opioid receptors in humans and those in laboratory animals. ${ }^{56}$ The majority of the mu-receptors in the spinal cord are found presynaptically on the afferent nociceptive terminals. ${ }^{55}$ Opioids that are mu and/or delta agonists cause a reduced release from $\mathrm{C}$-fibres of primary afferent neurotransmitters (substance $\mathrm{P}$ and glutamate). ${ }^{36,57,58}$ Opioids also inhibit the release of CGRP. ${ }^{59}$ The predominance of presynaptic opioid receptors on $\mathrm{C}$ fibres, as opposed to A-fibre terminals, accounts for the selective effect of spinal opioids on noxious evoked activity. ${ }^{60}$ The deeper layers of the spinal cord contain relatively fewer opioid receptors; those present are believed to be situated on nociceptive circuitry such that they have selective inhibitory effects. When stimulated, these postsynaptic opioid receptors hyperpolarize the membrane of dorsal horn neurons, thereby reducing activity in nociceptive pathways. ${ }^{57,61}$ Studies with agonists of the delta opioid receptors have highlighted their potential as analgesics possessing fewer of the side effects usually associated with morphine. However, experience with kappa receptor agonists, to date, has been disappointing. ${ }^{62}$

Supraspinal injections of $\mathrm{mu}$ and delta agonists will produce naloxone-sensitive analgesia, ${ }^{63}$ although the exact mechanism by which mu receptor activation produces supraspinal analgesia is still unknown. The exact role of the kappa receptors in the production of supraspinal analgesia is the subject of debate, with varying opinions ventured in the literature. ${ }^{61,64,65}$

Opioids also act peripherally as analgesic agents. $\mathrm{Mu}$ receptor agonists prevent the nociceptor sensitization induced by inflammatory mediators, such as prostaglandin $\mathrm{E}_{2}\left(\mathrm{PGE}_{2}\right){ }^{66}$ Delta and kappa receptors are thought to be located on the sympathetic nerves and to mediate analgesia peripherally by blocking bradykinin-induced release of nociceptor sensitizing agents from nerve endings. ${ }^{67}$ Thus, opioids act supraspinally, spinally and peripherally to produce analgesia, thereby reducing sensitization both centrally and peripherally. 


\section{NMDA receptor antagonists}

There are large numbers of NMDA receptors in the human spinal cord; ${ }^{40}$ the conditions necessary for their stimulation are complex and appear to only be achieved with repetitive C-fibre activity. ${ }^{68,69}$ When the $\mathrm{C}$-fibre stimulus is maintained and its frequency or intensity is sufficient, the NMDA receptor becomes activated and the resultant amplification or prolongation of the response seems to underlie many forms of central hyperalgesia. ${ }^{24,69-73}$ Prolonged inflammatory pain, unlike its acute pain counterpart, is sensitive to NMDA antagonism. ${ }^{74}$ Since the NMDA receptors have been implicated in pathological pain states, NMDA antagonists, such as ketamine or dextromethorphan, have been used to treat opioid insensitive neuropathic and cancer pains. NMDA antagonists have no effect on the afferent input onto dorsal horn, but they abolish the wind-up phenomenon, thereby converting the potentiated nociceptive response to a normal response. ${ }^{75}$ Opioids, by contrast, reduce the release of neurotransmitters by presynaptic C-fibres through binding to inhibitory receptors on the C-fibres. While opioids will delay the onset of wind-up by this mechanism, unless the dose is sufficient to stop all neurotransmitter release, wind-up may still occur. ${ }^{60}$ Opioids and NMDA antagonists may be used synergistically, and the combination has shown marked inhibition of nociceptive responses. Ketamine is an NMDA receptor antagonist at subanesthetic doses and therefore has the capability to block central hypersensitivity states at doses that are not directly analgesic. Spinally administered local anesthetics also work synergistically with morphine in modulating nociception by blocking afferent fibres and reducing neuronal excitability, thereby reducing NMDA-mediated activity. ${ }^{76}$

\section{Alpha 2 receptor antagonists}

Analgesia may also be produced by stimulation of alpha $_{2}$ adrenergic receptors in both the spinal cord and higher centres. ${ }^{77}$ These receptors may be activated by descending noradrenergic pathways or by exogenous compounds, such as epinephrine, clonidine or dexmedetomidine. Studies indicate that alpha ${ }_{2}$ agonists exert a potent analgesic response, ${ }^{78,79}$ and that their potency is increased by concomitant opioid therapy. ${ }^{80-82}$ While alpha ${ }_{2}$ agonists and opioids mediate their analgesic action through independent receptors, cross-tolerance may nonetheless develop between the two agents. ${ }^{83,84}$ Alpha $_{2}$-agonists also have been shown to reduce the undesirable physiological and psychological effects of opioid withdrawal. ${ }^{85}$ The exact mech anism by which alpha, agonists produce analgesia remains unknown, though it is postulated that release of acetylcholine may play a role. ${ }^{86,87}$

\section{Miscellaneous agents}

Numerous other agents have been shown to have analgesic properties and may have a role in producing preemptive analgesia, either singularly or in combination therapy.

Cholecystokinin (CCK) can selectively reduce the analgesic action of morphine at both spinal and supraspinal sites. It appears that CCK acts as an endogenous control on the level of mu analgesia. Upregulation of its receptors results in decreased analgesia in some neuropathic models; decreased CCK concentrations, in inflammatory models, results in enhancement of mu receptor effects. ${ }^{88}$ Alternatively, antagonists of the CCK receptor may enhance the analgesic action of opioids. ${ }^{89,90}$

It has been shown that NMDA receptor activation results in formation of nitric oxide (NO). Inhibitors of NO synthetase, the enzyme responsible for synthesis of NO, are antinociceptive, suggesting a possible future role in pain medicine. ${ }^{91}$ While it has been shown that GABA agonists also have antinociceptive actions, ${ }^{92}$ it remains to be determined whether the GABA receptor represents a viable target for future analgesic therapy.

Administration of antagonists to bradykinin, histamine and serotonin may be used to prevent or diminish the formation of neurogenic edema and sensitization of receptors. ${ }^{93}$ However, the complexity of the peripheral neural mechanisms leading to hyperalgesia is not yet fully understood. ${ }^{70,94}$ The role of newly discovered and longer established peripheral mediators such as the nerve growth factors, cytokines and catecholamines from sympathetic nerve endings, as well as bradykinin, serotonin and prostanoids, awaits elucidation. ${ }^{70,94}$ Accordingly, attention has focused on the CNS in the search for alternative processes that can be modified pharmacologically, in combination with peripherally acting measures, to improve analgesia. Monoamine reuptake inhibitors can enhance the antinociception produced by systemic opioids. ${ }^{95,96}$ Intrathecally administered anticholinesterases, such as neostigmine, can produce potent analgesia ${ }^{97}$ and can synergistically enhance the antinociception of both morphine and clonidine. ${ }^{98,99}$ Acetylcholinesterases appear to exert their analgesic action through a muscarinic, as opposed to a nicotinic, action (muscarinic agonists, but not nicotinic agonists, are analgesic when injected intrathecally). ${ }^{100,101}$ Amitryptiline, a tricyclic antidepressant, can enhance the antinociceptive effects of systemic opioids ${ }^{96}$ and of intrathecal neostigmine. ${ }^{98}$ Potassium channel 
openers, such as diazoxide and minoxidil, have also been shown to produce antinociception when administered intrathecally. ${ }^{102}$ Intrathecal administration of adenosine analogues produces antinociception; this effect can be blocked by the administration of adenosine receptor antagonists, such as methylxanthines. ${ }^{103,104}$ What role, if any, these agents will play in the treatment of pain requires further clinical investigation and will probably form a large portion of future research in this area.

\section{References}

1 Crile GW, Lower WE. Anoci-Association.

Philadelphia: Saunders, 1914: 223-5.

2 Keblet $H$. General vs. regional anesthesia. In: Rogers MC, Tinker JH, Covino BG, Longnecker DE (Eds.) Principles and Practice of Anesthesiology. St. Louis: Mosby, 1993: 1218-34.

3 Mendell LM. Physiological properties of unmyelinated fiber projection to the spinal cord. Exp Neurol 1966; 16: 316-32.

4 Birrell GJ, McQueen DS, Iggo A, Coleman RA, Grubb $B D$. $\mathrm{PGI}_{2}$-induced activation and sensitization of articular mechanonociceptors. Neurosci Lett 1991; 124: 5-8.

5 Levine JD, Fields HL, Basbaum AI. Peptides and the primary afferent nociceptor. J Neurosci 1993; 13: 2273-86

6 Cohen RH, Perl ER. Contributions of arachidonic acid derivatives and substance $P$ to the sensitization of cutaneous nociceptors. J Neurophysiol 1990; 64: 457-64.

7 Walker K, Perkins M, Dray A. Kinins and kinin receptors in the nervous system. Neurochem Int 1995; 26 $17-26$

8 Dray A. Inflammatory mediators of pain. Br J Anaesth 1995; 75: 125-31.

9 Suzuki H. Recent topics in the management of pain: development of the concept of preemptive analgesia. Cell Transplant 1995; 4(Suppl. 1): S3-6.

10 Lynn B. Neurogenic inflammation. Skin Pharmacol 1988; 1: 217-24.

11 Simone DA, Alreja M, LaMotte RH. Psychophysical studies of the itch sensation and itchy skin ("alloknesis") produced by intracutaneous injection of histamine. Somatosens Mot Res 1991; 8: 271-9.

12 Rang HP, Bevan S, Dray A. Nociceptive peripheral neurons: cellular properties. In: Wall PD, Melzack R (Eds.). Textbook of Pain, 3rd ed. Edinburgh: Churchill Livingstone, 1994: 57-78.

13 Capasso F, Dunn CJ, Yamamoto $S$, Willoughby DA, Giroud JP. Further studies on carrageenan-induced pleurisy in rats. J Pathol 1975; 116: 117-24.
14 Garcia Leme J, Hamamura L, Leite MP, Rocha e Silva $M$. Pharmacological analysis of the acute inflammatory process induced in the rat's paw by local injection of carrageenin and by heating. Br J Pharmacol 1973; 48: 88-96.

15 Holthusen H, Arndt JO. Nitric oxide evokes pain in humans on intracutaneous injection. Neurosci Lett 1994; 165: 71-4.

16 Wall PD. The dorsal horn. In: Wall PD, Melzack R (Eds). Textbook of Pain, 2nd ed. Edinburgh: Churchill Livingstone; 1994: 102-12.

17 Murase K, Randic M. Actions of substance P on rat spinal dorsal horn neurones. J Physiol (Lond) 1984; 346: 203-17.

18 Skofitsch G, Jacobowitz DM. Calcitonin gene-related peptide coexists with substance $P$ in capsaicin sensitive neurons and sensory ganglia of the rat. Peptides 1985; 6: 747-54.

19 Schaible H-G, Frendenberger U, Nengebaner V, Stiller $R U$. Intraspinal release of immunoreactive calcitonin gene-related peptide during development of inflammation in the joint in vivo - a study with antibody microprobes in cat and rat. Neuroscience 1994; 62: 1293-305.

20 Schneider SP, Perl ER. Selective excitation of neurons in the mammalian spinal dorsal horn by aspartate and glutamate in vitro: correlation with location and excitatory input. Brain Res 1985; 360: 339-43.

21 Kangrga I, Larew JSA, Randic $M$. The effects of substance $\mathrm{P}$ and calcitonin gene-related peptide on the efflux of endogenous glutamate and aspartate from the rat spinal dorsal horn in vitro. Neurosci Lett 1990; 108: 155-60.

22 Willcockson WS, Chung JM, Hori Y, Lee KH, Willis $W D$. Effects of iontophoretically released amino acids and amines on primate spinothalamic tract cells. J Neurosci 1984; 4: 732-40.

23 Dougherty PM, Willis WD. Enhancement of spinothalamic neuron responses to chemical and mechanical stimuli following combined micro-iontophoretic application of N-methyl-D-aspartic acid and substance P. Pain 1991; 47: 85-93.

24 Coderre TJ, Katz J, Vaccarino AL, Melzack R. Contribution of central neuroplasticity to pathological pain: review of clinical and experimental evidence. Pain 1993; 52: 259-85.

25 Tolle TR, Castro-Lopes JM, Evan G, Zieglgansberger $W$. C-fos induction in the spinal cord following noxious stimulation: prevention by opiates but not by NMDA antagonists. In: Bond MR, Charlton JE, Woolf CJ (Eds). Proceedings of the VIth World Congress on Pain. Elsevier Science BV, 1991: 299-305 
26 Willis WD Jr. Ascending somatosensory systems. In: Yaksh TL (Ed.). Spinal Afferent Processing. New York: Plenum Press, 1986: 398-416.

27 Melzack R, Casey KL. Sensory, motivational, and central control determinants of pain. A new conceptual model. In: Kenshalo DR (Ed.). The Skin Senses. Illinois: Thomas, 1968: 423-39.

28 Bowsher D. Role of the reticular formation in responses to noxious stimulation. Pain 1976; 2: 361-78.

29 Price DD, Dubner R, Hu JW. Trigeminothalamic neurons in nucleus caudalis responsive to tactile, ther mal, and nociceptive stimulation of monkey's face. J Neurophysiol 1976; 39: 936-53

30 Jensen TS, Yaksh TL. Brainstem excitatory amino acid receptors in nociception: microinjection mapping and pharmacological characterization of glutamate-sensitive sites in the brainstem associated with algogenic behavior. Neuroscience 1992; 46: 535-47.

31 Kikuchi H, Kitahata LM, Collins JG, Kawahara M, Nio $K$. Halothane-induced changes in neuronal activity of cells of the nucleus reticularis gigantocellularis of the cat. Anesth Analg 1980; 59: 897-901.

32 Mosso JA, Kruger L. Spinal trigeminal neurons excited by noxious and thermal stimuli. Brain Res 1972; 38 : 206-10.

33 Obtani M, Kikuchi H, Kitahata LM, et al. Effects of ketamine on nociceptive cells in the medial medullar reticular formation of the cat. Anesthesiology 1979; 51: 414-7.

34 ruge O, Kitahata LM, Collins JG, et al. Fentanyl and alfentanil suppress brainstem pain transmission. Anesth Analg 1985; 64: 597-600.

35 Sherrington SC. The Integrative Action of the Nervous System. New York: C. Scribner \& Son, 1906.

36 Besson J-M, Chaouch A. Peripheral and spinal mechanisms of nociception. Physiol Rev 1987; 67: 67-186.

37 Evans $R H$. The pharmacology of segmental transmission in the spinal cord. Prog Neurobiol 1989; 33: 255-79.

38 Fields HL, Heinricher MM, Mason P.

Neurotransmitters in nociceptive modulatory circuits. Ann Rev Neurosci 1991; 14: 219-45.

39 Yaksh TL. Behavioral and autonomic correlates of the tactile evoked allodynia produced by spinal glycine inhibition: effects of modulatory receptor systems and excitatory amino acid antagonists. Pain 1989; 37: 111-23.

40 Dickenson $A H$. Spinal cord pharmacology of pain. $\mathrm{Br}$ J Anaesth 1995; 75: 193-200.

41 Mollenholt P, Post C, Rawal N, Freedman J, Hokfelt T, Paulsson I. Antinociceptive and 'neurotoxic' action of somatostatin in rat spinal cord after intratheca administration. Pain 1988; 32: 95-105.
42 Woolf CJ, Chong M-S. Preemptive analgesia-treating postoperative pain by preventing the establishment of central sensitization. Anesth Analg 1993; 77: 362-79.

43 Willis WD Jr, Coggeshall RE. Sensory Mechanisms of the Spinal Cord, 2nd ed. New York: Plenum, 1991.

44 Hardy JD, Wolff HG, Goodell H. Experimental evidence on the nature of cutaneous hyperalgesia. J Clin Invest 1950; 29: 115-40.

45 LaMotte RH, Shain CN, Simone DA, Tsai EFP. Neurogenic hyperalgesia: psychophysical studies of underlying mechanisms. J Neurophysiol 1991; 66: 190-211.

46 Raja SN, Campbell JN, Meyer RA. Evidence for different mechanisms of primary and secondary hyperalgesia following heat injury to the glabrous skin. Brain 1984; 107(Pt 4): 1179-88.

47 Baumann TK, Simone DA, Shain CN, LaMotte RH. Neurogenic hyperalgesia: the search for the primary cutaneous afferent fibers that contribute to capsaicin induced pain and hyperalgesia. J Neurophysiol 1991; 66: 212-27.

48 LaMotte RH, Lundberg LER, Torebjork HE. Pain, hyperalgesia and activity in nociceptive $\mathrm{C}$ units in humans after intradermal injection of capsaicin. J Physiol (Lond) 1992; 448: 749-64.

49 Simone DA, Sorkin LS, Ob U, et al. Neurogenic hyperalgesia: central neural correlates in responses of spinothalamic tract neurons. J Neurophysiol 1991; 66: $228-46$

50 Torebjork HE, Lundberg LER, LaMotte RH. Central changes in processing of mechanoreceptive input in capsaicin-induced secondary hyperalgesia in humans. J Physiol (Lond) 1992; 448: 765-80.

51 Kitahata LM. Pain pathways and transmission. Yale Biol Med 1993; 66: 437-42.

52 Dabl JB, Keblet H. Non-steroidal anti-inflammatory drugs: rationale for use in severe postoperative pain. Br J Anaesth 1991; 66: 703-12.

53 Malmberg AB, Yaksh TL. Antinociceptive actions of spinal nonsteroidal anti-inflammatory agents on the formalin test in the rat. J Pharmacol Exp Ther 1992; 263: 136-46.

$54 \mathrm{McCormack} K$. The spinal actions of nonsteroidal anti-inflammatory drugs and the dissociation between their anti-inflammatory and analgesic effects. Drugs 1994; 47(Suppl 5): 28-45; Discussion 46-7.

55 Besse D, Lombard M-C, Zajac J-M, Roques BP, Besson $J-M$. Pre- and postsynaptic location of $\mathrm{mu}$, delta and kappa opioid receptors in the superficial layers of the dorsal horn of the rat spinal cord. Prog Clin Biol Res 1990; 328: 183-6.

56 Uhl GR, Childers S, Pasternak G. An opiate-receptor gene family reunion. Trends Neurosci 1994; 17: 89-93. 
57 Dickenson AH, Sullivan AF. Electrophysiological studies on the effects of intrathecal morphine on nociceptive neurones in the rat dorsal horn. Pain 1986; 24: 211-22

58 Kangrga I, Randic M. Outflow of endogenous aspartate and glutamate from the rat spinal dorsal horn in vitro by activation of low- and high-threshold primary afferent fibers. Modulation by mu-opioids. Brain Res 1991; 553: 347-52.

59 Pohl M, Lombard MC, Bourgoin S, et al. Opioid control of the in vitro release of calcitonin gene-related peptide from primary afferent fibres projecting in the rat cervical cord. Neuropeptides 1989; 14: 151-9.

60 Dickenson AH. A cure for wind up: NMDA receptor antagonists as potential analgesics. Trends Pharmacol Sci 1990; 11: 307-9.

61 Dickenson $A H$. Mechanisms of the analgesic actions of opiates and opioids. Br Med Bull 1991; 47: 690-702.

62 Calderon SN, Rothman RB, Porreca F, et al. Probes for narcotic receptor mediated phenomena. 19. Synthesis of $(+)-4$-[(alpha R)-alpha- $((2 S, 5 R)-4$-allyl2,5-dimethyl-1-piperazinyl)-3- methoxybenzyl]-N,N diethylbenzamide (SNC 80): a highly selective, nonpeptide delta opioid receptor agonist. J Med Chem 1994; 37: 2125-8.

63 Pleuvry BJ. Opioid receptors and their relevance to anaesthesia. Br J Anaesth 1993; 71: 119-26.

64 Leighton GE, Rodriguez RE, Hill RG, Hughes J. kopioid agonists produce antinociception after i.v. and i.c.v. but not intrathecal administration in the rat. $\mathrm{Br}$ J Pharmacol 1988; 93: 553-60.

65 Millan MJ. k-opioid receptors and analgesia. Trends Pharmacol Sci 1990; 11: 70-6.

66 Levine JD, Taiwo YO. Involvement of the mu-opiate receptor in peripheral analgesia. Neuroscience 1989; 32: $571-5$.

67 Taiwo YO, Levine JD. k- and delta-opioids block sympathetically dependent hyperalgesia. J Neurosci 1991; 11: 928-32.

68 Dickenson AH, Sullivan AF. Evidence for a role of the NMDA receptor in the frequency dependent potentiation of deep rat dorsal horn nociceptive neurones following $\mathrm{C}$ fibre stimulation.

Neuropharmacology 1987; 26: 1235-8.

69 Dickenson AH, Sullivan AF. Differential effects of excitatory amino acid antagonists on dorsal horn nociceptive neurones in the rat. Brain Res 1990; 506 31-9.

70 Dray A, Urban L, Dickenson A. Pharmacology of chronic pain. Trends Pharmacol Sci 1994; 15: 190-7.

71 Dubner R, Ruda MA. Activity-dependent neuronal plasticity following tissue injury and inflammation. Trends Neurosci 1992; 15: 96-103.
72 McMahon SB, Lewin GR, Wall PD. Central hyperexcitability triggered by noxious inputs. Curr Opin Neurobiol 1993; 3: 602-10.

73 Price DD, Mao J, Mayer DJ. Central neural mechanisms of normal and abnormal pain states. In: Fields HL, Liebeskind JC (Eds.). Pharmacological Approaches to the Treatment of Chronic Pain. Seattle: IASP Press, 1994: 61-84.

74 Haley JE, Sullivan AF, Dickenson AH. Evidence for spinal $\mathrm{N}$-methyl-D-aspartate receptor involvement in prolonged chemical nociception in the rat. Brain Res 1990; 518: 218-26.

75 Davies $S N$, Lodge D. Evidence for involvement of $\mathrm{N}$ methylaspartate receptors in 'wind-up' of class 2 neurones in the dorsal horn of the rat. Brain Res 1987; 424: 402-6.

76 Fraser HM, Chapman V, Dickenson AH. Spinal local anaesthetic actions on afferent evoked responses and wind-up of nociceptive neurones in the rat spinal cord: combination with morphine produces marked potentiation of antinociception. Pain 1992; 49: 33-41.

77 Wang $Y$-C, Su C-F, Lin $M-T$. The site and the mode of analgesic actions exerted by clonidine in monkeys. Exp Neurol 1985; 90: 479-88.

78 Fielding S, Wilker J, Hynes M, Szewczak M, Novick WJ $J r$, Lal $H$. A comparison of clonidine with morphine for antinociceptive and antiwithdrawal actions. J Pharmacol Exp Ther 1978; 207: 899-905.

79 De Kock M, Crochet B, Morimont C, Scholtes J-L. Intravenous or epidural clonidine for intra- and postoperative analgesia. Anesthesiology 1993; 79: 525-31.

80 Omote K, Kitahata LM, Collins JG, Nakatani K, Nakagawa $I$. Interaction between opiate subtype and alpha-2 adrenergic agonists in suppression of noxiously evoked activity of WDR neurons in the spinal dorsal horn. Anesthesiology 1991; 74: 737-43.

81 Wilcox GL, Carlsson K-H, Jochim A, Jurna I. Mutual potentiation of antinociceptive effects of morphine and clonidine on motor and sensory responses in rat spinal cord. Brain Res 1987; 405: 84-93.

82 Goyagi T, Nishikawa T. The addition of epinephrine enhances postoperative analgesia by intrathecal morphine. Anesth Analg 1995; 81: 508-13.

83 Paalzow $G$. Development of tolerance to the analgesic effect of clonidine in rats. Cross-tolerance to morphine. Naunyn Schmiedebergs Arch Pharmacol 1978; 304: 1-4.

84 Stevens CW, Monasky MS, Yaksh TL. Spinal infusion of opiate and alpha-2 agonists in rats: tolerance and cross-tolerance studies. J Pharmacol Exp Ther 1988; 244: 63-70 
85 Gold MS, Redmond DE Jr, Kleber HD. Clonidine blocks acute opiate-withdrawal symptoms. Lancet 1978; 2: 599-602.

86 Gordh T Jr, Jansson I, Hartvig P, Gillberg PG, Post C. Interactions between noradrenergic and cholinergic mechanisms involved in spinal nociceptive processing. Acta Anaesthesiol Scand 1989; 33: 39-47.

87 Detweiler DJ, Eisenach JC, Tong C, Jackson C. A cholinergic interaction in alpha 2 adrenoceptor-mediated antinociception in sheep. J Pharmacol Exp Ther 1993; 265: 536-42.

88 Stanfa LC, Sullivan AF, Dickenson AH. Alterations in neuronal excitability and the potency of spinal mu, delta and kappa opioids after carrageenan-induced inflammation. Pain 1992; 50: 345-54.

89 Stanfa L, Dickenson A, Xu XJ, Wiesenfeld-Hallin Z Cholecystokinin and morphine analgesia: variation on a theme. Trends Pharmacol Sci 1994; 15: 65-6.

90 Zhou $\Upsilon$, Sun $\Upsilon$-H, Zhang Z-W, Han J-S. Increased release of immunoreactive cholecystokinin octapeptide by morphine and potentiation of mu-opioid analgesia by CCKB receptor antagonist L-365,260 in rat spinal cord. Eur J Pharmacol 1993; 234: 147-54.

91 Moore PK, Wallace P, Gaffen Z, Hart SL, Babbedge $R C$. Characterization of the novel nitric oxide synthase inhibitor 7-nitro indazole and related indazoles: antinociceptive and cardiovascular effects. $\mathrm{Br}$ Pharmacol 1993; 110: 219-24.

92 Aanonsen LM, Wilcox GL. Muscimol, -aminobutyric $\operatorname{acid}_{\mathrm{A}}$ receptors and excitatory amino acids in the mouse spinal cord. J Pharmacol Exp Ther 1989; 248 : 1034-8.

93 Burch RM, Farmer SG, Steranka LR. Bradykinin receptor antagonists. Med Res Rev 1990; 10: 237-69.

94 Dray A, Perkins $M$. Bradykinin and inflammatory pain. Trends Neurosci 1993; 16: 99-104.

95 Taiwo YO, Fabian A, Pazoles CJ, Fields HL. Potentiation of morphine antinociception by monoamine reuptake inhibitors in the rat spinal cord. Pain 1985; 21: 329-37.

96 Botney M, Fields HL. Amitriptyline potentiates morphine analgesia by a direct action on the central nervous system. Ann Neurol 1983; 13: 160-4.

97 Bouaziz H, Tong C, Eisenach JC. Postoperative analgesia from intrathecal neostigmine in sheep. Anesth Analg 1995; 80: 1140-4

98 Eisenach JC, Gebhart GF. Intrathecal amitriptyline. Antinociceptive interactions with intravenous morphine and intrathecal clonidine, neostigmine, and carbamylcholine in rats. Anesthesiology 1995; 83: 1036-45.

99 Abram SE, Winne RP. Intrathecal acetyl cholinesterase inhibitors produce analgesia that is synergistic with morphine and clonidine in rats. Anesth Analg 1995; 81: 501-7.

100 Svensson BA, Sottile A, Gordh T Jr. Studies on the development of tolerance and potential spinal neurotoxicity after chronic intrathecal carbachol-antinociception in the rat. Acta Anaesthesiol Scand 1991; 35 141-7.

101 Gillberg PG, Hartvig P, Gordh T, et al. Behavioral effects after intrathecal administration of cholinergic receptor agonists in the rat. Psychopharmacology (Berl) 1990; 100: 464-9.

102 Welch SP, Dunlow LD. Antinociceptive activity of intrathecally administered potassium channel openers and opioid agonists: a common mechanism of action? I Pharmacol Exp Ther 1993; 267: 390-9.

103 Sawynok J, Sweeney MI, White TD. Classification of adenosine receptors mediating antinociception in the rat spinal cord. Br J Pharmacol 1986; 88: 923-30.

104 Sosnowski M, Stevens CW, Taksh TL. Assessment of the role of $A_{1} / A_{2}$ adenosine receptors mediating the purine antinociception, motor and autonomic function in the rat spinal cord. J Pharmacol Exp Ther 1989; 250: 915-22. 